\title{
Cloning of a novel thermostable glucoamylase from thermophilic fungus Rhizomucor pusillus and high-level co-expression with a-amylase in Pichia pastoris
}

Zhenggui He ${ }^{\dagger}$, Lujia Zhang ${ }^{\dagger}$, Youzhi Mao, Jingchao Gu, Qi Pan, Sixing Zhou, Bei Gao* and Dongzhi Wei*

\begin{abstract}
Background: Fungal amylase, mainly constitute of fungal a-amylase and glucoamylase, are utilized in a broad range of industries, such as starch hydrolysis, food and brewing. Although various amylases have been found in fungi, the amylases from Aspergillus dominate the commercial application. One of main problems exist with regard to these commercial use of amylases is relatively low thermal and acid stability. In order to maximize the efficiency of starch process, developing fungal amylases with increased thermostability and acid stability has been attracting researchers' interest continually. Besides, synergetic action of glucoamylase and a-amylase could facilitate the degradation of starch. And co-expressing glucoamylase with a-amylase in one host could avoid the need to ferment repeatedly and improves cost-effectiveness of the process.
\end{abstract}

Results: A novel fungal glucoamylase (RpGla) gene encoding a putative protein of 512 amino acid residues was cloned from Rhizomucor pusillus. BLAST analysis revealed that RpGla shared highest identity of $51 \%$ with the Rhizopus oryzae glucoamylase (ABB77799.1). The fungal glucoamylase RpGla was expressed in Pichia pastoris (KM71/9KGla) with maximum activity of $1237 \mathrm{U} \mathrm{ml}^{-1}$. The optimum pH and temperature of RpGla were $\mathrm{pH} 4.0$ and $70^{\circ} \mathrm{C}$, respectively. Fungal a-amylase (RpAmy) gene was also cloned from R. pusillus and transformed into KM71/9KGla, resulted in recombinant yeast KM71/9KGla-ZaAmy harboring the RpGla and RpAmy genes simultaneously. The maximum saccharogenic activity of KM71/9KGla-ZaAmy was $2218 \mathrm{U} \mathrm{ml}^{-1}$, which improved 79\% compared to KM71/ 9KGla. Soluble starch hydrolyzed by purified RpGla achieved $43 \%$ glucose and 34\% maltose. Higher productivity was achieved with a final yield of $48 \%$ glucose and $47 \%$ maltose catalyzed by purified enzyme preparation produced by KM71/9KGla-ZaAmy.

Conclusions: A novel fungal glucoamylase and fungal a-amylase genes were cloned from Rhizomucor pusillus. The two enzymes showed good thermostability and acid stability, and similar biochemical properties facilitated synergetic action of the two enzymes. A dramatic improvement was seen in amylase activity through co-expressing RpGla with RpAmy in Pichia pastoris. This is the first report of improving activity through co-expression glucoamylase with a-amylase in $P$. pastoris. Besides, fungal glucoamylase and a-amylase from $R$. pusillus were shown as promising candidates for further application in starch hydrolysis.

Keywords: Rhizomucor pusillus, glucoamylase, a-amylase, Co-expression, Pichia pastoris

\footnotetext{
* Correspondence: gaobei@ecust.edu.cn; dzhwei@ecust.edu.cn

${ }^{\dagger}$ Equal contributors

State Key Laboratory of Bioreactor Engineering, New World Institute of Biotechnology, East China University of Science and Technology, Shanghai 200237, China
} 


\section{Background}

Starch is one of the most abundant storage substances of plant. Amylases, which consist of multiple kinds of carbohydrase, hydrolyzing starch into diverse low molecular weight products, such as dextrin, maltose and glucose, are one of the most important enzymes [1,2]. Amylases are obtained from various sources including animals, plants and microorganisms, but only microbial amylase could meet the demands of industrial application due to its advantages in bulk production and other desired characteristics. Glucoamylase (EC 3.2.1.3) is an exo-acting enzyme which possesses strong activity of hydrolyzing polysaccharides into $\beta$-D-glucose by cleaving $\alpha-1,4$ glycosidic bond. Glucoamylase could also cleave $\alpha-1,6$ glycosidic bond, but at low rate. When at high concentration of glucose (35-40\%), glucoamylase would catalyze glucose into oligosaccharides by reverse reaction [3]. Alpha-amylase (EC 3.2.1.1) is an endoamylase which hydrolyzes internal $\alpha-1$, 4 glycosidic bond of starch, producing glucose, maltose and oligosaccharides [4].

Fungal amylase is more preferred in baking, brewing and sweeteners industries due to their more accepted generally recognized as safe status [5]. The processes of starch hydrolysis like saccharification need to perform at high temperature, however, the thermostabilities of most fungal glucoamylases are still not satisfactory. Therefore, developing fungal glucoamylase with increased thermostability especially at acidic condition will give an edge in the starch hydrolysis. To this, searching thermostable glucoamylase from thermophilic fungi provides a very attractive alternative. Although some thermostable glucoamylases from Streptosporangium sp. [6], Aspergillus fumigates [7,8] have been exploited, due to low yields and limited activity of these enzymes, nearly none of the thermostable fungal glucoamylase could meet the requirements of industrial production. So cloning the genes of thermostable fungal glucoamylase and heterologously expressing them in highlevel expression system has been regarded as a promising way to accelerate the application of thermostable enzymes.

Rhizomucor pusillus, a thermophilic fungus, growing well even at $50^{\circ} \mathrm{C}$, has been reported to be the source of amylase by Fergus [9] and Somkuti [10]. Deploey [11] later investigated the crude amylase produced by Mucor pusillus and found the optimal temperature and $\mathrm{pH}$ were $65^{\circ} \mathrm{C}$ and 4.5 , respectively. And Silva et al. [12] studied the dextrinogenic and saccharogenic activity of crude amylase of $R$. pusillus. Although Kanlayakrit et al. [13] purified and characterized a raw-starch-digesting glucoamylase from $R$. pusillus, the gene encoding glucoamylase of $R$. pusillus has not been cloned thus far.

Co-expressing two or more enzymes in one host which avoids repeated fermentation facilitates the complex operation of extracting and purifying, and improves the cost-effectiveness of the process. It is an applicable and economic formulation in enzyme production. However, no report is presented on co-expressing glucoamylase with $\alpha$-amylase in Pichia pastoris. Herein we reported on cloning a novel fungal glucoamylase and $\alpha$-amylase from $R$. pusillus and high-level expression in $P$. pastoris respectively. Furthermore, we firstly co-expressed the two enzymes in $P$. pastoris, improving both saccharogenic activity and dextrinogenic activity significantly.

\section{Results and discussion}

\section{Cloning and sequence analysis of RpGla and RpAmy} genes

A partial gene fragments of 792-bp was amplified from genomic DNA of $R$. pusillus GX-3 with the degenerate primers. Then, a contiguous sequence extended to 3,200-bp (glu) was obtained by genome-walking method.

Using primers containing putative start codon or stop codon (designed according to the analysis of the sequence of glu), paired with primers corresponding to the conservative amino acids, several fragments were amplified from first-strand cDNA of $R$. pusillus GX-3. After sequencing and assembling the obtained cDNA fragments, one complete open reading frame (ORF) was obtained, and then confirmed by continuous PCR amplification. The ORF of $R$. pusillus glucoamylase (named as RpGla) consisted of 1539bp nucleotides, encoding a putative protein of 512 amino acid residues. BLAST analysis revealed that RpGla shared the highest identity of $51 \%$ with the Rhizopus oryzae glucoamylase (ABB77799.1), indicating that RpGla was a novel glucoamylase. And the similarity with glucoamylse from Mucor circinelloides (AAN85206.1) and Aspergillus niger (AAT67041.1) were 50\%, 36\% respectively.

The RpGla was the second glucoamylase cloned from Rhizomucor sp.. Pedersen et al. [14] cloned the first glucoamylase gene from Rhizomucor sp. (Mucor circinelloides) for study of expression system, while did not investigate the enzymatic characterization.

RACE is the most widely used method to clone the full length cDNA sequence of eukaryotic gene, but it is costly and requires multiple steps. In this report, we tried to find the putative start codons and stop codons using the conserved sites as reference points. This successful attempt provided a helpful and effective method for cloning the cDNA of eukaryotic gene.

No signal peptide was present in the putative amino acid sequence of RpGla according to the analysis result using SignalP 4.0 program, implying that RpGla might be an intracellular or periplasmic enzyme.

The open reading frame of $R$. pusillus GX-3 $\alpha$-amylase (RpAmy) was cloned and analyzed. It consisted of 1416bp nucleotides, encoding a putative protein of 471 amino acid residues and had the highest similarity of 59\% with the $\alpha$-amylase from Rhizopus oryzae (ADL28123.1) [15]. 
Transformation, screening of Pichia pastoris transformants Increasing the copy number of expression cassette generally has the effect of increasing the amount of protein expressed in $P$. pastoris [16]. Transformants containing multiple copies of genes were obtained by electrotransformation and then screened on plates with higher concentrations of G418 or Zeocin. The colonies KM71/9KGla (RpGla expressed in P. pastoris) and KM71/ZaAmy (RpAmy expressed in $P$. pastoris) which chosen from YPDS plates containing $4.0 \mathrm{mg} \mathrm{ml}^{-1} \mathrm{G} 418$ and $200 \mu \mathrm{g} \mathrm{ml}^{-1}$ Zeocin respectively were inoculated on BMMY plates containing $2 \%(\mathrm{w} / \mathrm{v})$ soluble starch for amylase activity detecting. After incubating for 2 days, the colonies transformed with glucoamylase or $\alpha$ amylase gene all showed clearance zones, while the original $P$. pastoris showed no clearance zones. (Additional file 1: Figure S1). It was demonstrated that RpGla and RpAmy could be successfully expressed in $P$. pastoris and secreted into the medium.

Plasmid Z $\alpha$ Amy was then transformed into recombinant $P$. pastoris KM71/9KGla. Since the recombinant $P$. pastoris KM71/9KGla could not grow on Zeocin contained YPDS plates (Additional file 2: Figure S2), it was indicated that the colonies on YPDS plates containing Zeocin was transformed with pPICZ $\alpha$ Amy successfully. The resulted recombinant strain containing both fungal glucoamylase and $\alpha$-amylase was designated as KM71/9KGla-Z $\alpha$ Amy.

\section{High-level expression of glucoamylase and a-amylase in $P$. pastoris}

After induction at $30^{\circ} \mathrm{C}, 230 \mathrm{rpm}$ for $96 \mathrm{~h}$, the supernatants of KM71/9KGla, KM71/Z $\alpha$ Amy and KM71/9KGla-
ZaAmy all had a clear band between $45.0 \mathrm{kDa}$ and $66.2 \mathrm{kDa}$ (Figure 1a), while the supernatant of negative controls showed no band. The highest protein concentration of supernatant of KM71/9KGla-Z $\alpha$ Amy was $0.94 \pm 0.13 \mathrm{mg} \mathrm{ml}^{-1}$, which was increased $23 \%$ compared to that of KM71/9KGla $\left(0.76 \pm 0.08 \mathrm{mg} \mathrm{ml}^{-1}\right)$, and was greatly increased $298 \%$ compared to that of KM71/ Z $\alpha$ Amy $\left(0.24 \pm 0.03 \mathrm{mg} \mathrm{ml}^{-1}\right)$. The protein concentration of supernatant of negative controls were zero. Figure 2 illustrates the marked increase in activity. KM71/9KGla-Z $\alpha$ Amy achieved the highest saccharogenic activity (defined as the same with glucoamylase activity) of $2218 \mathrm{U} \mathrm{ml}^{-1}$, which was improved by $79 \%$ compared to that of KM71/9KGla (glucoamylase activity, $1237 \mathrm{U} \mathrm{ml}^{-1}$ ). The dextrinogenic activity (defined as the same with $\alpha$-amylase activity) of KM71/9KGlaZ $\alpha$ Amy has a maximum activity of $8285 \mathrm{U} \mathrm{ml}^{-1}$ and was improved by $183 \%$ compared to that of KM71/Z $\alpha$ Amy ( $\alpha$-amylase activity, $2927 \mathrm{U} \mathrm{ml}^{-1}$ ). No amylase activity was detected in the original $P$. pastoris host.

Recently, special attention was paid to thermostable glucoamylase-producing fungi, but low yield and low activity have always been the bottleneck for their industrial application. The maximum activity of thermostable glucoamylases from Streptosporangium sp. [6] and Humicola grisea var. ihermoidea [17] and Thermomyces lanuginosus [18] were only $41 \mathrm{U} \mathrm{ml}^{-1}, 15 \mathrm{U} \mathrm{ml}^{-1}$ and $1 \mathrm{U} \mathrm{ml}^{-1}$ respectively.

And the glucoamyalse and $\alpha$-amylase activity of crude enzyme produced by $R$. pusillus GX-3 were 6.9 and 108 $\mathrm{U} \mathrm{ml}^{-1}$ respectively. While the glucoamylase activity

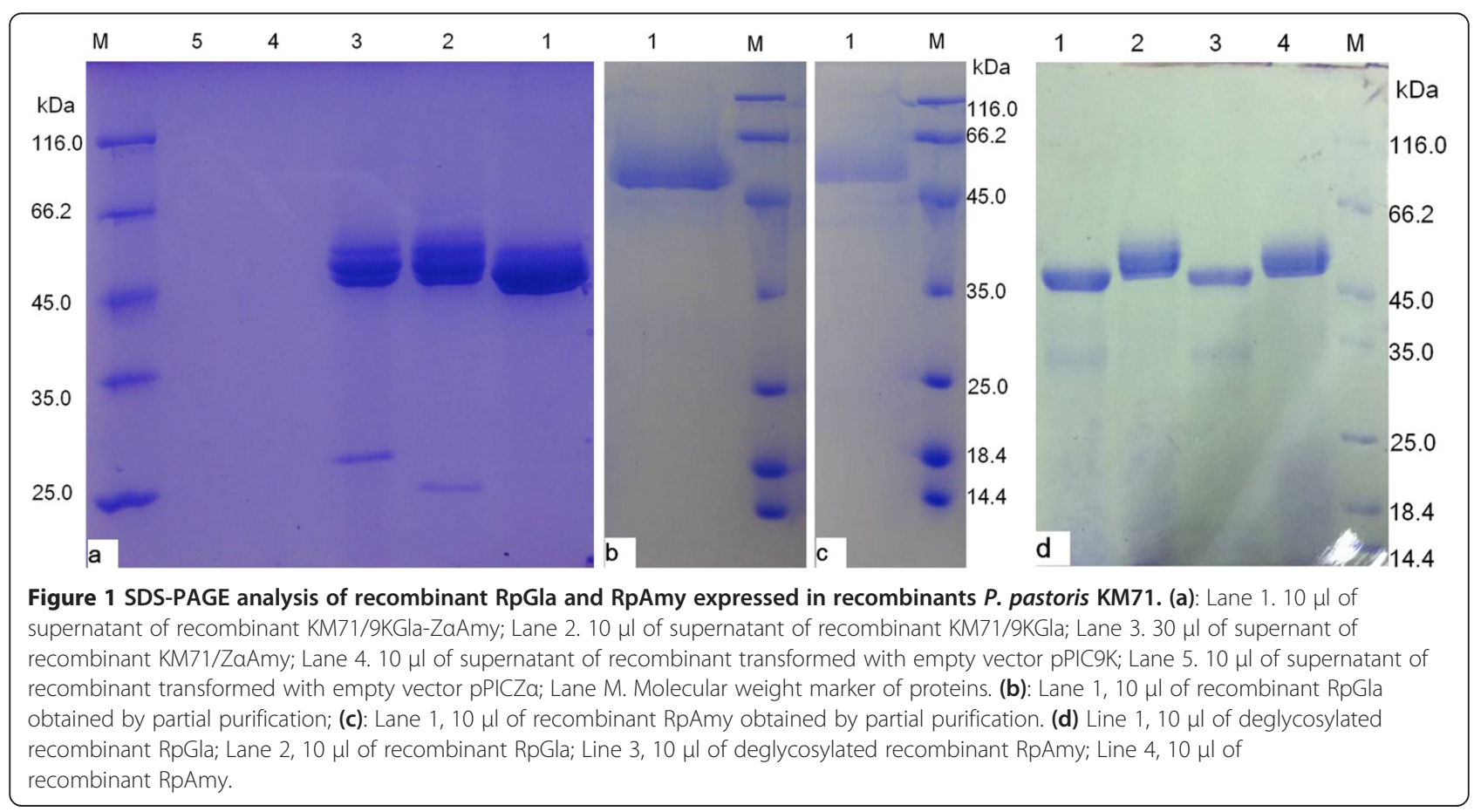



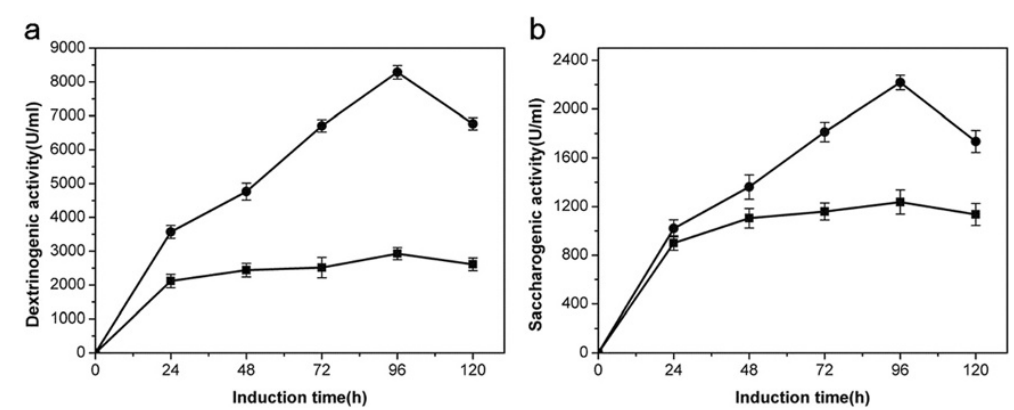

Figure 2 Glucoamylase and a-amylase production of recombinant $P$. pastoris. (a) Time course of saccharogenic activity of KM71/9KGla (घ)

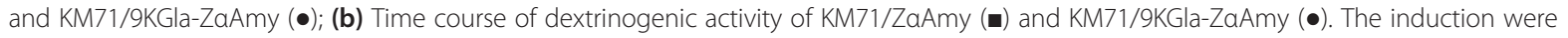
performed in $500 \mathrm{ml}$ shake flask with $50 \mathrm{ml} \mathrm{BMMY}$ media incubating in $30^{\circ} \mathrm{C}, 230 \mathrm{rpm}$. The induction period was 5 days with the addition of $0.5 \%$ ( $v / v)$ methanol per day.

(saccharogenic activity) of KM71/9KGla and KM71/ 9KGla-ZaAmy increased by 179 and 321 times respectively compared to $R$. pusillus GX-3. It indicated that in our study, the two enzymes which heterologously expressed in P. pastoris showed potential application in starch degradation.

\section{Purification and properties of recombinant glucoamylase and a-amylase}

The recombinant glucoamylase and $\alpha$-amylase were purified by ammonium sulfate, and then submitted to SDSPAGE analysis. The clear single band in Figure $1 \mathrm{~b}$ and $\mathrm{c}$ indicated that the single step was sufficient for purification of obtained enzymes.

The recombinant RpGla was purified 1.2-fold with homogeneity and a recovery of $39 \%$. The recombinant RpAmy was purified 1.7-fold with homogeneity and a recovery of $38 \%$. The specific activity of purified RpGla and RpAmy were $1953 \mathrm{U} \mathrm{mg}^{-1}$ (glucoamylase activity) and $20732 \mathrm{U} \mathrm{mg}^{-1}$ ( $\alpha$-amylase activity).

Based on the gel filtration of purified recombinant RpGla (Additional file 3: Figure S3), there were two absorbance peaks corresponding to MW $114.5 \mathrm{kDa}$ and $54.8 \mathrm{kDa}$ respectively. While treated with boiling, the previous absorbance peak became smaller obviously (Additional file 3: Figure S3a). According to the SDSPAGE analysis (Figure 1b), RpGla showed single band with estimated molecular weight of $45 \sim 66.2 \mathrm{kDa}$, and the theoretical molecular weight of RpGla was about $57 \mathrm{kDa}$. Therefore, the recombinant RpGla was inferred to be a dimer with a MW of $114.5 \mathrm{kDa}$.

The recombinant RpAmy showed the same phenomenon as RpGla. Two absorbance peaks corresponding to MW $114.9 \mathrm{kDa}$ and $55.5 \mathrm{kDa}$ respectively were presented (Additional file 3: Figure S3d). After boiled in water, the previous absorbance peak became much smaller (Additional file 3: Figure S3c). In view of the SDS-PAGE analysis, RpAmy showed single band with estimated molecular weight of 45 $\sim 66.2 \mathrm{kDa}$, and the theoretical molecular weight of RpAmy was about $50 \mathrm{kDa}$. Therefore, the recombinant RpAmy was deduced to be a dimer with a MW of $114.9 \mathrm{kDa}$.

When submitted the translated amino acid sequence of RpGla and RpAmy to prediction of disulfide bond, little possibility of presence of disulfide bond was showed. So the dimer may be as a result of hydrophobic and polar interaction and be nonobligatory [19].

Lane 2 and Lane 4 in Figure 1d showed the deglycosylated recombinant RpAmy and RpGla respectively. The molecular weight of both recombinant proteins became a little smaller as a result of deglycosylation. According to the prediction results of glycosylation sites on NetNGlyc 1.0 (www.cbs.dtu.dk/services/), RpGla and RpAmy have 2 and 5 potential $\mathrm{N}$-glycosylation sites respectively. So, RpGla and RpAmy expressed in Phichia Pastoris were glycoproteins.

The RpGla and RpAmy both exhibited activity in acidic conditions ( $\mathrm{pH}$ 3.0-6.0) with optimum at $\mathrm{pH} 4.0$ and 5.0 (Figure 3a) respectively, and were stable in a wide range of $\mathrm{pH}$ 4.0-9.0 (Figure $3 \mathrm{~b}$ ). The optimal temperature for both enzymes was $70^{\circ} \mathrm{C}$ (Figure 3c). The RpGla and RpAmy showed relative good stability at $60^{\circ} \mathrm{C}$. The residual activity of RpGla and RpAmy were 73\% (Figure 3e) and 85\% (Figure 3d), respectively, when incubated at $60^{\circ} \mathrm{C}$ for $30 \mathrm{~min}$. The half-life (T1/2) of RpGla and RpAmy at $60^{\circ} \mathrm{C}$ were $164 \mathrm{~min}$ and $75 \mathrm{~min}$ respectively according to calculation based on kinetics of thermal deactivation of enzymes.

One of the main problems with regard to the industrial application of fungal glucoamylase is the relatively low thermal stability [20], like commercially available $A s$ pergillus niger glucoamylase. Here, the thermal stabilities of RpGla and RpAmy were greatly higher than most other fungal amylases $[1,3]$, making them a great potential for starch hydrolysis procedures.

Kanlayakrit et al. [13] have reported the purification and characterization of raw-starch-digesting glucoamylase from thermophilic Rhizomucor pusillus. The optimal temperature and $\mathrm{pH}$ were $65^{\circ} \mathrm{C}, 4.6$ respectively, which 


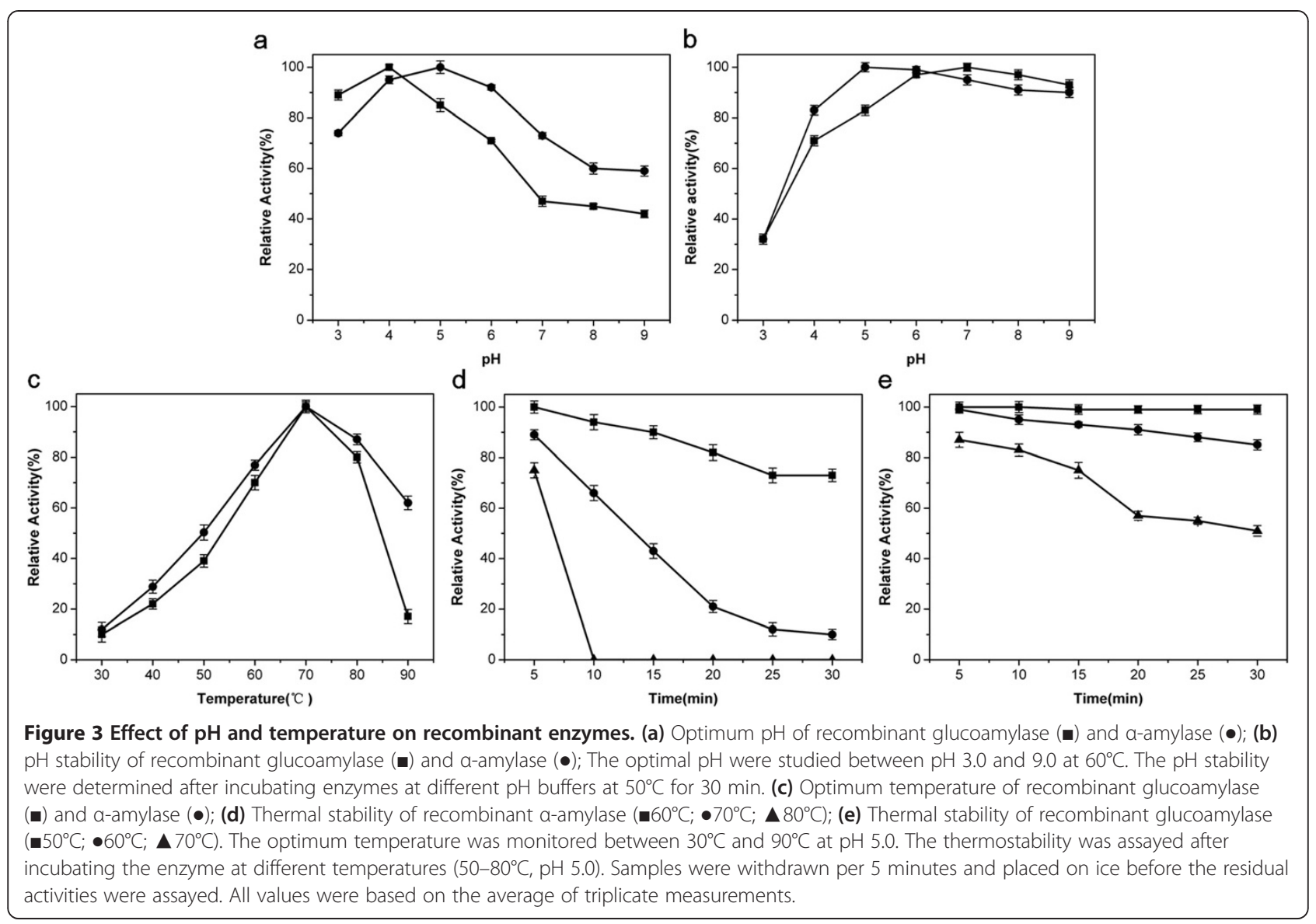

were similar to the characteristics of RpGla in this work. However, in Kanlayakrit's work, the activity of crude enzyme preparation was $17.7 \mathrm{U} \mathrm{ml}^{-1}$ and the specific activity was $57.7 \mathrm{U} \mathrm{mg}^{-1}$, which were both much lower than that of RpGla. Besides, as it is very common to have more than one glucoamylases in a fungus, thus it requires further study to explore whether the glucoamylase studied by Kanlayakrit was the same with RpGla.

Considering the similar biochemical properties of RpGla and RpAmy, one clear advantage was that the two enzymes could perform their best at the same condition. Consequently, we firstly co-expressed the glucoamylase with $\alpha$ amylase in $P$. pastoris and exploit synergism in starch degradation. As described above, both saccharogenic activity and dextrinogenic activity were significantly enhanced by employing co-expression. Meanwhile, the excellent productivity of two enzymes in one host would provide cost reduction in fermentation, purification, and substantial savings in energy consumption. Note that the saccharogenic activity did not increase proportionally to the increase amount of recombinant $\alpha$-amylase, it may ascribed to the fact that adding a few $\alpha$-amylase into glucoamylase could facilitate the degradation of starch [21]. Since $\alpha$-amylase hydrolyzes internal $\alpha-1,4$ glycosidic bond of starch randomly, providing more nonreducing chain ends, which could serve as substrate of glucoamylase, so the saccharogenic activity increased substantially.

Furthermore, according to the hydrolysis result (Table 1) of different starch catalyzed by the enzyme preparation, the saccharogenic activities towards all selected substrates were greatly enhanced by co-expression. Therefore, co-expression

Table 1 The hydrolysis of various substrates catalyzed by RpGla and RpAmy

\begin{tabular}{llcc}
\hline Substrate & \multicolumn{2}{l}{ Relatively activity (\%) } \\
\cline { 2 - 4 } & RpGla & RpAmy & Co-expression $^{\mathbf{a}}$ \\
\hline Soluble starch & $55.8 \pm 3.1$ & $54.2 \pm 2.7$ & 100 \\
maize starch & $28.6 \pm 0.8$ & $34.9 \pm 1.7$ & $61.5 \pm 2.8$ \\
potato starch & $30.6 \pm 1.8$ & $28.8 \pm 1.5$ & $51.6 \pm 2.4$ \\
amylopectin & $66.4 \pm 2.0$ & $29.9 \pm 0.7$ & $79.2 \pm 2.1$ \\
amylose & $6.0 \pm 0.2$ & $5.2 \pm 0.2$ & $10.1 \pm 0.4$ \\
glycogen & $5.5 \pm 0.2$ & $5.8 \pm 0.3$ & $12.0 \pm 0.5$ \\
\hline
\end{tabular}

aenzyme preparation produced by KM71/9KGla-ZaAmy. Substrates $(0.05 \mathrm{~g})$ in $0.1 \mathrm{M}$ citric acid-sodium citrate buffer $(\mathrm{pH} 5.0,5 \mathrm{ml}$ ) was mixed with $0.5 \mathrm{ml}$ appropriately diluted enzyme. The reaction was carried out at $60^{\circ} \mathrm{C}$ for $10 \mathrm{~min}$, and terminated by adding $1 \mathrm{ml}$ of 3,5-dinitrosalicylic acid and boiled for 5 minutes. 
of the RpGla and RpAmy demonstrated advantages in liquefaction of different starch and other carbohydrate.

\section{Analysis of hydrolysis products}

According to HPLC analysis result (Figure 4a), the main products of soluble starch hydrolyzed by purified RpGla were glucose (43\%) and maltose (34\%) with no detection of other oligosaccharides. Utilizing purified RpAmy as catalyst, the main products were maltose $(69 \%)$ and glucose (22\%) (Figure $4 \mathrm{~b}$ ) with no detectable maltotriose and maltotetraose. However, the main products hydrolyzed by purified mixed enzyme preparation of KM71/9KGlaZ $\alpha$ Amy were glucose $(48 \%)$ and maltose $(47 \%)$ with no detectable of maltotriose and maltotetraose (Figure 4c).

No extra peaks except glucose were detected up to $24 \mathrm{~h}$ of incubation even at high concentration (40\%) (Figure 4d), which meant that the recombinant RpGla did not show any transglycosylation activity on glucose. Usually, transglycosylation activity of glucoamylase will lead to the formation of oligosaccharides from glucose with condensation reaction [22].

Therefore, the enhancement of hydrolysis reaction of recombinant glucoamyalse after adding recombinant $\alpha$ amylases may owe to increased quantity of oligosaccharides and maltose that catalyzed by $\alpha$-amylase [23].

\section{Conclusions}

A novel fungal glucoamylase and the $\alpha$-amylase genes were cloned from Rhizomucor pusillus, and expressed successfully in Pichia pastoris. The two recombinant enzymes have similar characteristics with optimal $\mathrm{pH}$ of 4.0 (RpGla) and 5.0 (RpAmy) respectively and optimal temperature as high as $70^{\circ} \mathrm{C}$, thus the operating range in terms of $\mathrm{pH}$, temperature and compatibility with other enzymes all improved. When co-expressing RpGla with RpAmy, the amylase activity improved significantly, and was much higher than most other thermostable fungal glucoamylases and $\alpha$-amylases. The improved amylase activity through co-expressing glucoamylase with $\alpha$ amylase in $P$. pastoris is first reported in this paper. Therefore, the work we did may offer an effective method to prepare high-activity biocatalyst. Meanwhile, the outstanding biochemical properties indicate emerging and promising application of $R$. pusillus glucoamyalse and $\alpha$-amylase.

\section{Methods}

\section{Strains, plasmids}

Rhizomucor pusillus GX-3 was isolated in Henan, China. The strain grew well even at $\mathrm{pH} 4.0,50^{\circ} \mathrm{C}$. Escherichia coli DH5 $\alpha$ and Pichia pastoris KM71 were used as hosts for DNA manipulation and gene expression. The vectors pMD19-T, pPIC9K and pPICZ $\alpha$ were used for sequencing and expression of the amplified genes.

\section{Cloning and sequence analysis of glucoamylase and a-amylase}

Preparation of genomic DNA was carried out according to the instructions of Fungal DNA Kit (Omega, USA). Total RNA was isolated from the mycelia of $R$. pusillus using RNAiso Plus (Takara). First-strand cDNA were synthesized using PrimeScript 1st Strand cDNA Synthesis Kit (Takara).

Two degenerated primers R.pGJf/R.pGJr (Table 2) corresponding respectively to the conserved catalytic domains WGRPQ(N)DGPA and GRYPED of glucoamylase amino acid sequence were designed to amplify fragments of the glucoamylase gene from $R$. pusillus. Genomic DNA and first-strand cDNA of $R$. pusillus GX-3 were used as templates respectively. The obtained DNA fragment was used as a starting template for chromosome-walking to obtain the full length of $R$. pusillus glucoamylase (RpGla). Subsequently, a contiguous sequence extended to 3,200 bp (glu) was obtained and confirmed by PCR amplification with primers R.pGWf/R.pGWr.

In order to clone the full length cDNA of glucoamylase, four primers (Table 2) containing putative start codon, one primer containing putative stop codon and two specific primers corresponding to the conservative amino acids (R.pGf, R.pGr) were designed based on the analysis of glu. The first-strand cDNA of $R$. pusillus GX3 was used as template. The PCR products were sequenced and analyzed to reconstitute the putative open reading frame of $R$. pusillus glucomylase.

The cDNA of $\alpha$-amylase gene was amplified with specific primers R.pAf and R.pAr (Table 2) using the firststrand cDNA of R.pusillus GX-3 as template. The signal peptides of deduced amino acid sequences were predicted on the SignalP 4.0 (www.cbs.dtu.dk/services/).

\section{Construction of the expression vectors and transformation of $P$. pastoris}

The genes encoding the mature RpGla and RpAmy were amplified using primer pairs R.pGEf/R.pGNr and R.pAEf/ R.pANr (Table 2), then cloned into pPIC9K and pPICZ $\alpha$, respectively. Recombinant vectors $9 \mathrm{KGla}$ and Z $\alpha \mathrm{Amy}$ were transformed into $P$. pastoris KM71 by electrotransformation according to methods of Invitrogen manual, resulted transformants KM71/9KGla and KM71/Z $\alpha$ Amy, respectively. Transformants KM71/9KGla were seeded onto YPDS plates containing G418 at different concentration from $1 \mathrm{mg} \mathrm{ml}^{-1}$ to $4 \mathrm{mg} \mathrm{ml}^{-1}$ to screen multicopy transfomants. Transformants KM71/ZaAmy were spread for selection on YPDS plates containing Zeocin of $100 \mu \mathrm{g} \mathrm{ml}^{-1}, 200 \mu \mathrm{g} \mathrm{ml}^{-1}$.

In order to express glucoamylase and $\alpha$-amylase simultaneously in P. patoris, plasmid Z $\alpha$ Amy was transformed into KM71/9KGla. The resulted recombinant containing both glucoamylase and $\alpha$-amylase (designated as KM71/ 


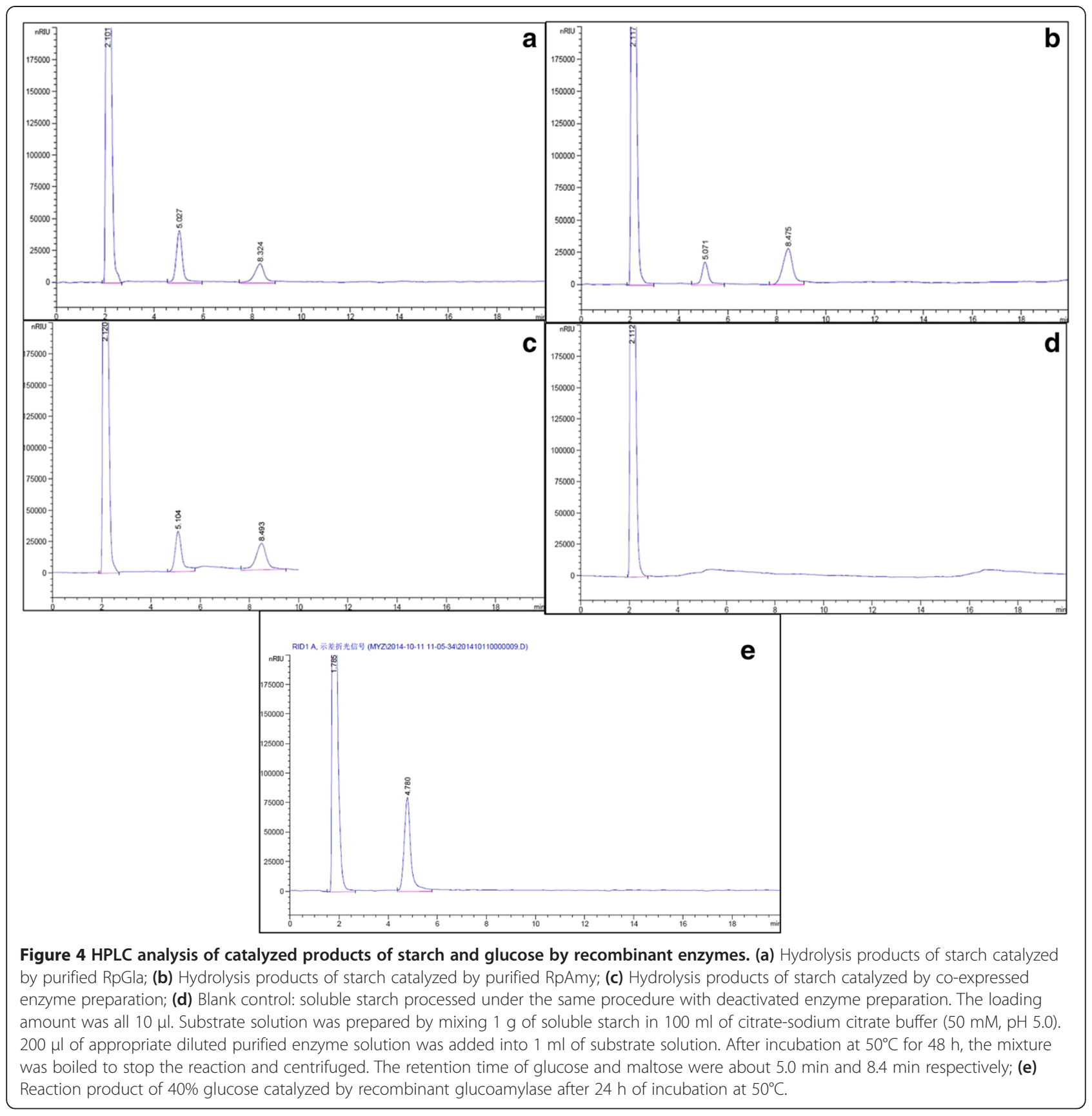

9KGla-ZaAmy) selected multi-copy clones by different concentration of Zeocin. The empty vectors pPIC9K and pPICZ $\alpha A$ were transformed into KM71 as negative control.

\section{Expression and Purification of RpGla and RpAmy}

Transformants KM71/9KGla and KM71/Z $\alpha$ Amy were inoculated on BMMY plates containing $2 \%(\mathrm{w} / \mathrm{v})$ soluble starch to detect amylase activity. Recombinant $P$. pastoris which showed high amylase activity on BMMY plates were inoculated into $50 \mathrm{ml}$ BMGY medium. The flasks were incubated in $30^{\circ} \mathrm{C}, 225 \mathrm{rpm}$. When $\mathrm{OD}_{600}$ reached 6.0 , cells of $250 \mathrm{ml}$ culture were harvested and then cultured in $50 \mathrm{ml} \mathrm{BMMY}$ media incubating in $30^{\circ} \mathrm{C}, 230 \mathrm{rpm}$ to induce expression. The induction period was 5 days with the addition of $0.5 \%(\mathrm{v} / \mathrm{v})$ methanol per day.

In order to test the production stabilities of the recombinant strain, more than three batches of production were performed at the same condition. The crude $\alpha$-amylase in the supernatant was harvested by centrifugation. Solid ammonium sulphate was added into the crude supernatant $(100 \mathrm{ml})$ up to $30 \%$ saturation, and the precipitated 
Table 2 Primers used for PCR

\begin{tabular}{|c|c|c|}
\hline Primers & Function & Sequence $\left(5^{\prime}-3^{\prime}\right)$ \\
\hline R.pGJf & \multirow[t]{2}{*}{ Primers for conserved regions of glucoamylase gene } & TGGGGHMGHCCNCARAATGAYGG \\
\hline R.pGJr & & RTCGTCAGGRTANCKRCCRATDGC \\
\hline $5-1 S P 1$ & \multirow[t]{3}{*}{ Primers for 5'-flanking region of glucoamylase gene } & TCTTCCCTAGAATTGATGCGTGTGA \\
\hline $5-1 S P 2$ & & AGTCTAAATCCTTGAATATCGCCGG \\
\hline $5-1 \mathrm{SP} 3$ & & AAGGATAAAGGTCGATGCACGCAGT \\
\hline $5-2 S P 1$ & \multirow[t]{3}{*}{ Primers for 5'-flanking region of glucoamylase gene } & ATCCTCСTCCTCCCATGAAGAAACA \\
\hline $5-2 S P 2$ & & AGCAATATGTTGGTTGCGGTTGATC \\
\hline $5-2 S P 3$ & & GAAAAGCATCAGCAGCACCTGAATC \\
\hline 3-1SP1 & \multirow[t]{3}{*}{ Primers for 3'-flanking region of glucoamylase gene } & TGGATGTTTCTATCCTATTGGCAGC \\
\hline $3-2 S P 2$ & & CCACATAAATATGGATCCATTGCCG \\
\hline 3-3SP3 & & TTGTATCCACTCAATCGGGAGCAGC \\
\hline R.pGWr & \multirow[t]{2}{*}{ Primers for glucoamylase gene glu' } & GATGAAAGCAGCGTACGACCATGTC \\
\hline R.pGWf & & TGTGCAAGAATCTACCCTITTCGAG \\
\hline R.pGf1 & \multirow[t]{4}{*}{ Primers containing putative start codon for cDNA of glucoamylase gene } & ATGCGTTATGCAACCCCGC \\
\hline R.pGf2 & & ATGCTCTTCGCTTITTGCTATTGT \\
\hline R.pGf3 & & ATGTCTTACCGGAAGCAATTTCT \\
\hline R.pGf4 & & ATGGGAGGAGGAGGATCTTGGT \\
\hline R.pGr1 & Primers containing putative stop codon for cDNA of glucoamylase gene & GGCGTTATTTATTACCCTCTTITGACC \\
\hline R.pGf & \multirow[t]{2}{*}{ Primers for cDNA of glucoamylase gene } & ATGGACACGCGATTCAGCCC \\
\hline R.pGr & & AGCGTACGACCATGTCAGGTCG \\
\hline R.pGEcoRf & \multirow[t]{2}{*}{ Primers containing restriction enzyme sites for cDNA of glucoamylase gene } & GGAATTCATGCGTTATGCAACCCCGC \\
\hline R.pGNotr & & TTGCGGCCGCTTACCCTCTITTGACCA \\
\hline R.pAf & \multirow[t]{2}{*}{ Primers for cDNA of a-amylase gene } & ATGAAATTCAGCATCTCTCTCTCGG \\
\hline R.pAr & & TTAAGCAGAGGTGAAGATAGCGGA \\
\hline R.pAEf & \multirow[t]{2}{*}{ Primers containing restriction enzyme sites for cDNA of a-amylase gene } & GAATTCAGCCCTTTGCCCCAACAGCA \\
\hline R.pANr & & TTGCGGCCGCTTAAGCAGAGGTGAAGATAG \\
\hline
\end{tabular}

The primers are denoted as follows: the start codon and stop codon are underlined; the cons'ervative codons are boxed; the dotted line indicated restriction enzyme sites.

proteins were removed. Then adding solid ammonium sulphate up to $70 \%$ saturation, and collecting the precipitated recombinant enzyme. The precipitate was redissolved in $10 \mathrm{ml}$ of $50 \mathrm{mM}$ phosphate buffer ( $\mathrm{pH}$ 6.0) and dialyzed overnight against the same buffer at $4^{\circ} \mathrm{C}$. The dialysis was performed twice by renewing the buffer. The purified proteins were detected by SDS-PAGE, and the protein concentration were determined according to the method of Bradford [24]. All values are average values obtained from three independent experiments.

The molecular weight of the purified enzymes was estimated by gel filtration using Superdex 200 10/300 GL (GE Healthcare)equilibrated and eluted with $50 \mathrm{mM}$ phosphate buffer plus $0.15 \mathrm{M} \mathrm{NaCl}, \mathrm{pH}$ 6.5. The standard proteins (Thyroglobulin bovine, MW $\sim 670000, \gamma-$ globulins from bovine blood, MW 150 000, Albumin chicken egg grade VI, MW $\sim 44300$, Ribonuclease A type I-A from bovine pancreas, MW 13 700) used as MW markers were purchased from Sigma. The loading sample was $100 \mu \mathrm{l}$. The experiment was conducted on ÄKTA ${ }^{\mathrm{m}}$ system (GE Healthcare).

For the deglycosylation study, $10 \mu \mathrm{l}$ purified recombinant RpGla or RpAmy were treated with $2 \mathrm{mU}$ of Glycopeptidase F (Takara Biotechnology Co. Ltd, Dalian, China) for $17 \mathrm{~h}$ at $37^{\circ} \mathrm{C}$ according to the manufacturer's instructions. The samples were run in SDS-PAGE for analysis.

\section{Enzyme assay}

The glucoamylase activity or saccharogenic activity was estimated on the basis of increase in reducing sugars [25]. Soluble starch $(0.05 \mathrm{~g})$ in $0.1 \mathrm{M}$ citric acid-sodium citrate buffer (pH 5.0, $5 \mathrm{ml}$ ) was mixed with $0.5 \mathrm{ml}$ appropriately diluted enzyme. The reaction was carried out at $60^{\circ} \mathrm{C}$ for $10 \mathrm{~min}$, and terminated by adding $1 \mathrm{ml}$ of 3, 5-dinitrosalicylic acid and boiled for 5 minutes. One unit of glucoamylase activity or saccharogenic activity was defined as the amount of enzyme that released reducing sugars equivalent to $1 \mu \mathrm{mol}$ of glucose per minute under the above conditions. 
The activity of $\alpha$-amylase activity or dextrinogenic activity was determined according to method described by Liu and $\mathrm{Xu}[26,27]$. $0.5 \mathrm{ml}$ of appropriately diluted enzyme and $5 \mathrm{ml}$ of $0.5 \%(\mathrm{w} / \mathrm{v})$ soluble starch dissolved in $0.1 \mathrm{M}$ citric acid-sodium citrate buffer ( $\mathrm{pH} 5.0$ ) was incubated at $60^{\circ} \mathrm{C}$. The reaction was terminated by the addition of $5 \mathrm{ml}$ of chilled 0.1 M HCl. One unit of $\alpha$-amylase activity or dextrinogenic activity was defined as the amount of enzyme that hydrolysis $1 \mathrm{mg}$ of soluble starch in 5 minutes under the above conditions.

Maize starch, potato starch, amylopectin, amylose and glycogen were used to explore the extensive applicability of the synergic action of RpGla and RpAmy. The reactions were carried out as detection of saccharogenic activity [25]. The soluble starch catalyzed by purified enzyme preparation produced by KM71/9KGla-Z $\alpha$ Amy was regarded as control. The results were assayed and expressed as a percentage of the control values. All values were based on the average of triplicate measurements.

\section{Characterization of RpGla and RpAmy}

The optimal $\mathrm{pH}$ of purified RpGla and RpAmy were studied between $\mathrm{pH} 3.0$ and 9.0 (100 mM Gly-HCl buffer for $\mathrm{pH}$ 3.0, $100 \mathrm{mM}$ citric acid-sodium citrate buffer for $\mathrm{pH}$ 4.0-5.0, $100 \mathrm{mM}$ sodium phosphate buffer for $\mathrm{pH}$ 6.07.0, $100 \mathrm{mM}$ Tris- $\mathrm{HCl}$ for $\mathrm{pH} 8.0-9.0)$ at $60^{\circ} \mathrm{C}$. The $\mathrm{pH}$ stability profiles were determined by assaying the residual activity after incubating enzymes at different $\mathrm{pH}$ buffers at $50^{\circ} \mathrm{C}$ for $30 \mathrm{~min}$. The optimum temperature of purified RpGla and RpAmy were monitored between $30^{\circ} \mathrm{C}$ and $90^{\circ} \mathrm{C}$ at $\mathrm{pH}$ 5.0. To test the thermostability, enzymes were incubated at different temperatures $\left(50-70^{\circ} \mathrm{C}, \mathrm{pH} 5.0,100 \mathrm{mM}\right.$ citric acid-sodium citrate buffer). Samples were withdrawn per 5 minutes and placed on ice before the residual activities were assayed. All values were based on the average of triplicate measurements.

In order to investigate the hydrolysis product of starch catalyzed by purified RpGla and RpAmy, substrate solution was prepared by mixing $1 \mathrm{~g}$ of soluble starch in $100 \mathrm{ml}$ of citrate-sodium citrate buffer (50 mM, pH 5.0). $200 \mu \mathrm{l}$ of appropriate diluted purified enzyme solution was added into $1 \mathrm{ml}$ of substrate solution. After incubation at $50^{\circ} \mathrm{C}$ for $48 \mathrm{~h}$, the mixture was boiled to stop the reaction and centrifuged. The supernatant subjected to HPLC analysis. HPLC was performed on series 1200 HPLC system (Agilent Technologies, USA) using $\mathrm{NH}_{2}-$ HPLC column $(3.5 \mathrm{um}, 3.0 \times 250 \mathrm{~mm})$ from Waters eluting with acetonitrile/water $(85: 15)$ at a flow rate of $0.8 \mathrm{ml} \mathrm{min}^{-1}$.

To check whether the recombinant RpGla has transglycosylation activity, the enzyme was incubated with different glucose concentrations (10, 20, and 40\%) under $\mathrm{pH} 5.0$ and $50^{\circ} \mathrm{C}$. After incubation for $6,12,24 \mathrm{~h}$, the reaction mixture was boiled to stop the reaction and centrifuged and then subjected to HPLC analysis for oligosaccharides detection [22].

The data sets supporting the results of this article are included within the article and its additional files.

\section{Nucleotide sequence accession numbers}

The mRNA of $R$. pusillus glucoamylase and $\alpha$-amylase had been submitted into the GenBank database under the accession numbers KC479790 and KC479791 respectively.

\section{Additional files}

\begin{abstract}
Additional file 1: Figure S1. Screening and detecting amylase activity of recombinant $P$. pastoris on BMMY plates containing $2 \%$ soluble starch. (a) KM71/9KGla; (b) KM71/ZaAmy; (c) P. pastoris KM71 transformed with empty vector pPIC9K or pPICZa.

Additional file 2: Figure S2. Screening transformants KM71/9KGla-ZaAmy on YPDS plates containing $200 \mathrm{\mu g} \mathrm{ml}^{-1}$ Zeocin. (a) Recombinants KM71/9KGla inoculated on YPDS plates containing $200 \mathrm{~g} \mathrm{~m}^{-1}$ Zeocin; (b) Recombinants KM71/9KGla transformed with plasmid ZaAmy inoculated on YPDS plates containing $200 \mathrm{\mu g} \mathrm{ml}^{-1}$ Zeocin.

Additional file 3: Figure S3. Elution profiles of boiled recombinant RpGla(a), recombinant RpGla(b), boiled recombinant RpAmy(c) and recombinant RpAmy. The gel filtration was conducted on $\ddot{A K T} A^{T M}$ system (GE Healthcare) with Superdex 200 10/300 GL(GE Healthcare)equilibrated and eluted with $50 \mathrm{mM}$ phosphate buffer plus $0.15 \mathrm{M} \mathrm{NaCl}, \mathrm{pH}$ 6.5. The flow rate was $0.5 \mathrm{ml} / \mathrm{min}$. The standard proteins (Thyroglobulin bovine, MW 670 000,Y-globulins from bovine blood, MW 150 000, Albumin chicken egg grade VI, MW 44 300, Ribonuclease A type I-A from bovine pancreas, MW 13 700) used as MW markers were purchased from Sigma. The loading sample was $100 \mu \mathrm{l}$. The two absorbance peaks were corresponding to MW about $114 \mathrm{kDa}$ and $55 \mathrm{kDa}$ sequentially.
\end{abstract}

\section{Competing interests}

The authors declare that they have no competing interests.

\section{Authors' contributions}

$\mathrm{ZH}$ carried out project design, gene cloning, sequence analysis, vector construction, and drafted the manuscript. LZ and YM carried out $P$. pastoris transformation, expression and purification. JG, QP and SZ carried out enzyme determination and characterization. BG and DW critically guided project design and revised and corrected the manuscript. All authors read and approved the final manuscript.

\section{Acknowledgements}

This work was funded by The National Natural Foundation of China (NO. 31201296), the Fundamental Research Funds for the Central Universities, the National High Technology Research and Development Program of China (No. 2013AA102109), and the National major science and technology projects of China (No. 2012ZX09304009).

Received: 30 April 2014 Accepted: 18 December 2014

Published online: 24 December 2014

\section{References}

1. Gupta R, Gigras P, Mohapatra H, Goswami VK, Chauhan B: Microbial a-amylases: a biotechnological perspective. Process Biochem 2003, 38:1599-1616.

2. van der Maarel MJ, van der Veen B, Uitdehaag JC, Leemhuis H, Dijkhuizen L: Properties and application of starch-converting enzymes of the aamylase family. J Biotechnol 2002, 94:137-155.

3. James JA, Lee BH: Glucoamylases: microbial sources, industrial application and molecular biology-a review. J Food Biochem 1997, 21:1-52.

4. Nigam P, Singh D: Enzyme and microbial systems involved in starch processing. Enzyme Microb Technol 1995, 17:770-778.

5. Li S, Zuo ZR, Niu DD, Singh S, Permaul K, Prior BA, Shi G, Wang Z: Gene cloning, heterologous expression, and characterization of a high 
maltose-producing a-amylase of Rhizopus oryzae. Appl Biochem Biotechnol 2011, 164:581-592.

6. Stamford TLM, Stamford NP, Coelho LCBB, Araujo JM: Production and characterization of a thermostable glucoamylase from Streptosporangium sp. endophyte of maize leaves. Bioresour Technol 2002, 83:105-109.

7. Pasamontes L, Haiker M, Wyss M, Tessier M, Loon APV: Gene cloning, purification, and characterization of a heat-stable phytase from the fungus Aspergillus fumigatus. Appl Environ Microbiol 1997, 63:1696-1700.

8. Silva WBD, Peralta RM: Purification and characterization of a thermostable glucoamylase from Aspergillus fumigates. Can J Microbio/ 1998, 44:493-497.

9. Fergus CC: The production of amylase by some thermophilic fungi. Mycologia 1969, 61:1171-1175.

10. Somkuti GA, Steinberg DH: Thermoacidophilic extracellular amylase of Mucor pusillus. Dev Ind Microbiol 1980, 21:327-333.

11. Deploey JJ, Nasta M, Adams PR: Quantitative-determinations of the temperature and $\mathrm{pH}$ stability of extracellular amylase obtained from Mucor Pusillus. Mycologia 1982, 74:847-850.

12. Silva TM, Attili-Angelis D, Carvalho AFA, Silva RD, Boscolo M, Gomes E: Production of saccharogenic and dextrinogenic amylases by Rhizomucor pusillus A 13.36. J Microbiol 2005, 43:561-568.

13. Kanlayakrit W, Ishimatsu K, Nakao M, Hayashida S: Characteristics of raw-starch-digesting glucoamylase from thermophilic Rhizomucor pusillus. J Ferment Technol 1987, 65:379-385.

14. Pedersen PA, Houghton-Larsen J: Cloning and characterisation of a glucoamylase gene (GlaM) from the dimorphic zygomycete Mucor circinelloides. Appl Microbiol Biotechnol 2003, 62:210-217.

15. Li S, Zuo ZR, Niu DD, Singh S, Permaul K, Prior BA, Shi GY, Wang ZX: Gene cloning, heterologous expression, and characterization of a high maltose-producing alpha-amylase of Rhizopus oryzae. Appl Biochem Biotechnol 2011, 2011(164):581-592.

16. Clare JJ, Rayment FB, Ballantyne SP, Sreerkrishna K, Romanos MA: High-level expression of tetanus toxin fragment $\mathrm{C}$ in Pichia pastoris strains containing multiple tandem integrations of the gene. Nat Biotechnol 1991, 9:455-460.

17. Tosi LRO, Terenzi HF, Jorge JA: Purification and characterization of an extracellular glucoamylase from the thermophilic fungus Humicola grisea var. ihermoidea. Can J Microbiol 1993, 39:846-852.

18. Li DC, Yang YJ, Peng YL, Shen CY: Purification and characterization of extracellular glucoamylase from the thermophilic Thermomyces lanuginosus. Mycol Res 1998, 102:568-572.

19. Susan J, Janet MT: Principles of protein-protein interactions. Proc Natl Acad Sci 1996, 93:13-20.

20. Nielsen BR, Svendsen A, Pedersen H, Vind J, Hendriksen HV, Frandsen TP Glucoamylase Variants. US Patent 2002, US 6352851B1.

21. Abe J, Nakajima K, Nagano H, Hizukuri S: Properties of the raw-starch digesting amylase of Apergillus sp. I-27: a synergistic action of glucoamylase and a-amylase. Carbohydr Res 1988, 175:85-92.

22. Pardeen K, Asimul I, Faizan A, Satyanarayana T: Characterization of a neutral and thermostable Glucoamyalse from the thermophilic mold Thermomucor indicae-seudaticae: activity, stability, and structural correlation. Appl Biochem Biotechnol 2010, 160:879-890.

23. Rastall RA, Adlard MW, Bucke C: Synthesis of hetero-oligosaccharides by glucoamylase in reverses. Biotechnol Lett 1991, 13:501-504.

24. Bradford M: A rapid and sensitive method for the quantitation of microgram quantities of protein utilizing the principle of protein-dye binding. Anal Biochem 1976, 72:248-254.

25. Miller GL: Use of dinitrosalicylic acid regent for determination of reducing sugar. Anal Chem 1951, 31:426-428.

26. Liu XD, Xu Y: A novel raw starch digesting a-amylase from a newly isolated Bacillus sp. YX-1: Purification and characterization. Bioresour Technol 2008, 99:4315-4320.

27. Yoo YJ, Hong J, Hatch RT: Comparison of a-amylase activities from different assay methods. Biotechnol Bioeng 1987, 30:147-151.

\section{Submit your next manuscript to BioMed Central and take full advantage of:}

- Convenient online submission

- Thorough peer review

- No space constraints or color figure charges

- Immediate publication on acceptance

- Inclusion in PubMed, CAS, Scopus and Google Scholar

- Research which is freely available for redistribution

Submit your manuscript at www.biomedcentral.com/submit
C Biomed Central 